University of Nebraska - Lincoln

DigitalCommons@University of Nebraska - Lincoln

Faculty Publications from the Harold W. Manter Laboratory of Parasitology

2000

\title{
The Systematics of the Genus Trichinella with a Key to Species
}

K. D. Murrell

Animal Parasitic Disease Lab, ARS, United States Department of Agriculture

J. Ralph Lichtenfels

Animal Parasitic Disease Lab, ARS, United States Department of Agriculture, 2jrcgl@gmail.com

Dante S. Zarlenga

Animal Parasitic Disease Lab, ARS, United States Department of Agriculture

E. Pozio

Instituto Superiore di Sanita

Follow this and additional works at: https://digitalcommons.unl.edu/parasitologyfacpubs

Part of the Parasitology Commons

Murrell, K. D.; Lichtenfels, J. Ralph; Zarlenga, Dante S.; and Pozio, E., "The Systematics of the Genus Trichinella with a Key to Species" (2000). Faculty Publications from the Harold W. Manter Laboratory of Parasitology. 632.

https://digitalcommons.unl.edu/parasitologyfacpubs/632

This Article is brought to you for free and open access by the Parasitology, Harold W. Manter Laboratory of at DigitalCommons@University of Nebraska - Lincoln. It has been accepted for inclusion in Faculty Publications from the Harold W. Manter Laboratory of Parasitology by an authorized administrator of DigitalCommons@University of Nebraska - Lincoln. 


\title{
The systematics of the genus Trichinella with a key to species
}

\author{
K.D. Murrell ${ }^{\mathrm{a}, *}$, R.J. Lichtenfels ${ }^{\mathrm{a}}$, D.S. Zarlenga ${ }^{\mathrm{a}}$, E. Pozio ${ }^{\mathrm{b}}$ \\ a Agricultural Research Service, US Department of Agriculture, Beltsville, MD 20705, USA \\ ${ }^{\mathrm{b}}$ Laboratory of Parasitology, Instituto Superiore di Sanita, Rome 00161, Italy
}

\begin{abstract}
The authors review the major biological, biochemical, and molecular characters that are used to distinguish the seven Trichinella species (T. spiralis, T. nativa, T. britovi, T. pseudospiralis, T. murrelli, T. nelsoni, T. papuae) and three genotypes whose taxonomic status is yet uncertain (T-6, T-8, T-9). A comparison of host specificity, morphology, reproductive abilities, nurse cell development and freeze resistance is presented, along with useful biochemical and molecular markers. Finally, this information is used to construct a diagnostic key for the species. A phylogenetic classification of the species is needed. (C) 2000 Elsevier Science B.V. All rights reserved.
\end{abstract}

Keywords: Biogeography; History of trichinellosis; T. spiralis; T. nativa; T. britovi; T. pseudospiralis; T. murrelli; T. nelsoni; T. papuae

\section{Introduction}

From the time of the discovery of Trichinella in 1835 until the middle of the next century, it was commonly assumed that all trichinellosis was caused by a single species, Trichinella spiralis (Owen, 1835). This nematode was discovered by James Paget and Richard Owen in 1835 in the muscles of human cadavers in London and by Joseph Leidy in 1846 in the muscles of swine in Philadelphia (Gould, 1970). More than a century later, T. spiralis had been reported from more than 100 different naturally or experimentally infected mammalian hosts and was believed to be a single species with low host specificity and spread around the world with the movement of domestic swine. The pivotal events that led eventually to the current taxonomy of Trichinella were the experimental attempts to infect laboratory rodents and pigs with isolates from wild animals. The experimental observations of Nelson and Mukundi (1963) and Nelson et al. (1966) revealed marked strain differences

\footnotetext{
${ }^{*}$ Corresponding author. Tel.: +1-301-504-5084; fax: +1-301-504-7302.

E-mail address: kdm@kul.ok (K.D. Murrell).
} 
among geographical isolates of Trichinella. They observed that isolates with high infectivity for rats were also highly infective for domestic swine (Sus scrofa), while isolates such as those from the Kenyan bush pig (Potamocherus porcus) and the Alaskan bear (Ursus arctos) had low infectivity for both rats and pigs. This contradicted the widely held dogma that $T$. spiralis had little or no host specificity among mammals. Subsequently, Gretillat and Vassiliades (1968) and Kruger et al. (1969) reported similar results from comparative infection studies in pigs and dogs with West African and South African wild animal isolates. Kozar and Kozar (1965) carried out detailed host infectivity studies on Trichinella isolates of a "laboratory strain" (from Polish pigs) and the isolate from Kenya (Nelson and Mukundi, 1963). Again, the Kenyan isolate exhibited much lower infectivity for mice than the pig isolate. However, they observed some changes in isolate infectivity after passages through laboratory mice. Similar observations were reported by Arakawa and Todd (1971). These observations contributed to the inclination of many workers in this field to regard the differences observed in different geographical and host species isolates of T. spiralis as a result of differences in methods and hosts used by individual investigators (Zimoroi, 1963), and a reluctance to consider that experimental differences reflected distinct and consistent genetic differences. The absence of clear morphological distinctions among isolates with different host infectivities also hindered alternative proposals. Host infectivity results did, however, raise two important questions regarding the systematics and epidemiology of Trichinella: (1) what are the significant "biological variants" in sylvatic hosts with regard to the domestic cycle of trichinellosis (infectivity for farm swine), and (2) does the "pig strain" adapt to wild animals, at a cost of its infectivity for domestic pigs and rats? These issues helped to stimulate greater interest in the epidemiology and genetics of Trichinella spp. The year 1972 proved especially momentus for the systematics of this genus, including the description of a new, very distinct, non-encapsulating, bird-infecting species, Trichinella pseudospiralis (Garkavi, 1972) and the proposal, as separate species, of two encapsulating species Trichinella nelsoni and Trichinella nativa (Britov and Boev, 1972). These publications led to even greater research activity across a broad front which added greatly to the biological and morphological characterization of increasing numbers of Trichinella isolates.

With the exception of the non-encapsulating species, the usual morphological criteria (Table 1) for separating helminth species have not proved adequate for speciating Trichinella (Dick, 1983; Lichtenfels et al., 1983; Pozio et al., 1992a). However, an interesting observation on the sperm structure of T. spiralis was reported by Hulinska and Shaikenov (1983), who reported that in contrast to T. nativa and T. pseudospiralis, T. spiralis sperm are surrounded by a tubular sheath with evaginations that form tubules in the cytoplasm. Other distinctions observed were associated with the sperm plasmalemma and number of mitochondria. These differences may affect the ability of some species to interbreed, although this needs verification.

A plethora of molecular techniques have been generated in recent years for differentiating Trichinella genotypes (Mydynski and Dick, 1985; Zarlenga and Barta, 1990; La Rosa et al., 1992), culminating most recently in the development of multiplex (Zarlenga et al., 1999) and cytochrome oxidase I-based (Nagano et al., 1999) PCR tests. Initial work focused on the cloning of the ribosomal DNA (rDNA) repeat from Trichinella genotypes (Boyd et al., 1989; Zarlenga and Murrell, 1989), though information had been presented earlier 


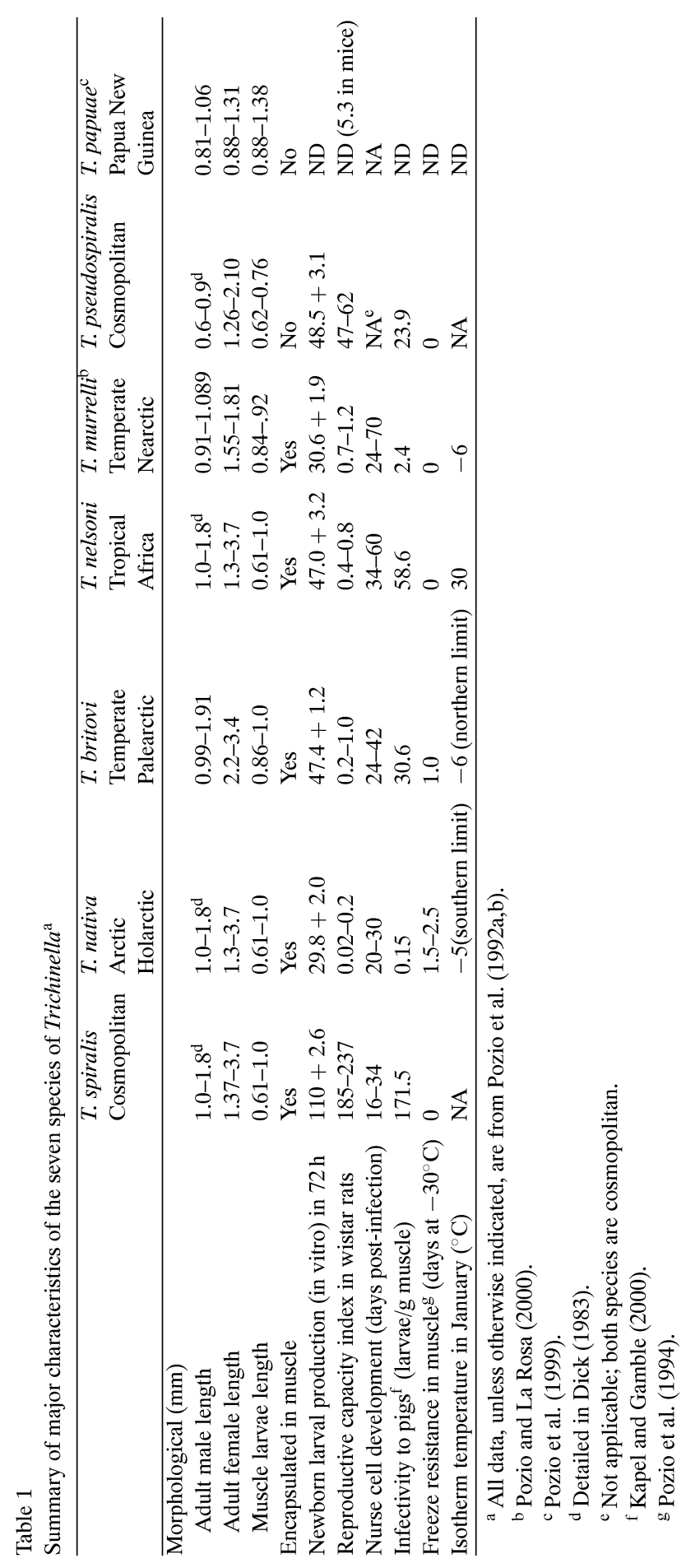


showing genetic variability within the genus using restriction fragment length polymorphisms (RFLP) (Chambers et al., 1986) and Southern blotting of the rDNA (Dame et al., 1987). Boyd et al. (1989) cloned and mapped restriction enzyme differences within both the intergenic and the gene encoding regions of the rDNA repeat from T. spiralis, T. pseudospiralis and what is now known to be T. nativa from arctic fox. This was the first study that focused on variation within the internal transcribed spacer (ITS) regions in this genus. Zarlenga and Murrell (1989) followed by generating characteristic rDNA-based, Dra I-generated RFLP banding patterns primarily for use in a diagnostic key to differentiate T. spiralis, $T$. pseudospiralis, T. nativa, T. nelsoni and the more recently named Trichinella murrelli (formerly $\mathrm{T}-5$ ) that were used also as important components in the separation of this genus into at least five species.

The paradigm of Trichinella taxonomy changed convincingly after the publication of a series of detailed and thorough comparative studies (biological and biochemical) on 300 Trichinella isolates from the International Trichinella Reference Centre (ITRC) by Pozio et al. (La Rosa et al., 1992; Pozio et al., 1992a,b). These studies clarified much of the confusion surrounding the vast accumulation of data on host infectivity studies, temperature tolerances and introduced important new data on biochemical characteristics. The resulting scheme retained $T$. spiralis sensu stricto, $T$. nativa, $T$. pseudospiralis, restricted $T$. nelsoni to include only isolates from equatorial Africa and established an additional species, Trichinella britovi.

In addition to these five species, Pozio et al. (1992a) recognized three unique groups of isolates or genetic types (termed T-5, T-6 and T-8) for which insufficient information was available to determine their systematic status. Subsequently, a large number of isolates of T-5 from sylvatic carnivores of North America was studied (Minchella et al., 1989; Snyder et al., 1993) and deposited in ITRC (Pozio et al., 1989; La Rosa et al., 1992). Studies at the ITRC have recently led to the establishment of a sixth species, T. murrelli (Pozio and La Rosa, 2000), for the species in wildlife in the temperate regions of North America previously designated T-5. The status of T-6, a genetic type similar to T. nativa, parasitic in temperate Nearctic wildlife, but with a lower level of resistance to freezing and distinct molecular differences, is not yet resolved (Bandi et al., 1995; Pozio et al., 1992a). T-8 is most closely related to T. britovi, but it is not resistant to freezing and occurs only in wildlife in South Africa (Bandi et al., 1995; Wu et al., 1998, 1999; Pozio et al., 1992a). A ninth genotype, T-9, has been identified in Japanese wildlife (Nagano et al., 1999).

A seventh species, the second with non-encapsulating muscle larvae, was recently discovered in domestic and sylvatic swine of Papua New Guinea. It has been described as Trichinella papuae by Pozio et al. (1999). In addition to lacking a cyst in the muscle stage, the muscle larvae are 1/3 longer than those of $T$. pseudospiralis, it is not infective for birds and it has distinct sequence differences in the expansion segment $\mathrm{V}$ of the large subunit of the rDNA gene.

The following sections review the important biological, morphological and biochemi$\mathrm{cal} / \mathrm{molecular}$ characteristics of the seven species and three genetic phenotypes of uncertain taxonomic status (T-6, T-8 and T-9). Concluding remarks include a summary of the diagnostic characteristics of the species in the form of a diagnostic key to species. A more complete summary of the major morphological, biological and molecular species characters is presented in Table 1. 


\section{Distinctive species characteristics}

For a detailed and comprehensive description of the species of Trichinella, particularly synonyms, biochemical, molecular and morphological features, the reader is referred to Pozio et al. (1992a,b, 1999), and Pozio and La Rosa (2000). The following discussion focuses on those aspects that uniquely identify species of the genus Trichinella and provide characters for diagnostic differentiation. Emphasis is placed on biological characteristics which provide adaptive significance, rather than morphological distinctions, which are few. Chief among the biological distinctions are host range and temperature tolerances. Distinguishing molecular/biochemical markers are also indicated. The intent is to familiarize the reader with not only those features that distinguish the various species, but also to highlight those traits that govern important epidemiological characteristics (Table 2).

\subsection{T. spiralis (Owen, 1835)}

Prior to the events described above, this genus consisted of only one species, T. spiralis (syn. T-1), with a very wide host range. The synanthropic $T$. spiralis is now widely recognized to be the only species with high infectivity for domestic pigs ( $S$. scrofa), commensal rats (Rattus spp.) and mice (Mus musculus). This biological hallmark has been demonstrated by numerous authors (Nelson and Mukundi, 1963; Kozar and Kozar, 1965; Britov, 1974; Chadee and Dick, 1982; Kjos-Hanssen, 1984; Murrell et al., 1985, 1986; Kapel et al., 1998; Webster et al., 1999). Importantly, T. spiralis is also infective to sylvatic hosts, particularly wild boars, bears, and rodents, making the potential for wild animals as reservoirs for swine trichinellosis real (Dame et al., 1987; Murrell et al., 1987). More recently T. spiralis has been identified in North American red foxes and coyotes (Appleyard et al., 1996). This is a trait that must be considered in determining the feasibility of any proposed eradication program.

T. spiralis has a higher newborn larvae production in vitro ( $>90$ larvae/72 $\mathrm{h}$ ) than other species of the genus (Table 1); all other species under similar in vitro conditions produce fewer than 60 larvae/72 h (Pozio et al., 1992b). T. spiralis also is the least freeze-resistant species; at $-30^{\circ} \mathrm{C}, T$. spiralis larvae are killed within $12 \mathrm{~h}$ in mouse muscle (Pozio et al., 1994), and within $48 \mathrm{~h}$ at $-20^{\circ} \mathrm{C}$ (Martinez-Fernandez et al., 1998).

T. spiralis can be identified by several biochemical and molecular characters. This species is specifically characterized by six unique allozyme banding patterns generated by ACP, ALAT, EST, GLDH, PGM and SOD (La Rosa et al., 1992). This pattern was verified in 61 geographical isolates. Parasites of this species specifically bind repetitive DNA probes such as the pPRA (Klassen et al., 1986), pBP2 (Dame et al., 1987) and pT1.6 (La Rosa et al., 1994). Furthermore, they can be identified by a characteristic, single 173 bp PCR fragment via multiplex PCR (Zarlenga et al., 1999) and by a characteristic, single $444 \mathrm{bp}$ PCR fragment using the primer set SB4-2 (Wu et al., 1997). Within the PCR-amplified, mitochondrial DNA (mtDNA) derived, cytochrome oxidase I (COX I) gene, a panel of four restriction fragments 22, 70, 126 and $201 \mathrm{bp}$ in length are generated by Mse I digestion (Nagano et al., 1999). Other T. spiralis molecular markers (using restriction fragment length polymorphism-RFLP) (Zarlenga et al., 1991) and random amplified polymorphic DNA (RAPD)-derived primers (Wu et al., 1998, 1999) have also been established. 
Table 2

Key to established species of Trichinella ${ }^{\mathrm{a}}$

I. Encapsulates in muscle ${ }^{b}$

High infectivity for rats and pigs; cosmopolitan distribution rDNA multiplex PCR fragment $173 \mathrm{bp}^{\mathrm{c}}$

Very low infectivity for rats and pigs

Distributed in Equatorial Africa; rDNA multiplex PCR fragments 155 and 404 bp

Distributed in arctic, subarctic or temperate regions

Arctic and subarctic latitudes of Holarctic region; high resistance to freezing; rDNA multiplex PCR fragment $127 \mathrm{bp}$

Temperate latitudes; moderate, or no resistance to freezing

Palearctic distribution; moderate resistance to freezing; rDNA multiplex PCR fragments 127 and $252 \mathrm{bp}$

Nearctic distribution; no resistance to freezing; rDNA multiplex PCR fragments 127 and $316 \mathrm{bp}$

T. spiralis

T. nelsoni

T. nativa

T. britovi

Muscle larva length less than $0.8 \mathrm{~mm}$; infective for chickens; rDNA multiplex PCR fragments 300 and $360 \mathrm{bp}$

Muscle larva length more than $0.8 \mathrm{~mm}$; not infective for chickens; rDNA multiplex PCR fragment $240 \mathrm{bp}$

${ }^{\mathrm{a}}$ Information on an additional three genotypes (T-6, T-8 and T-9) is included in the text of this review.

${ }^{\mathrm{b}}$ For extensive list of characteristics of species, see text of this review and Table 1.

${ }^{\mathrm{c}}$ Procedure described in Zarlenga et al. (1999). 


\subsection{T. nativa (Britov and Boev, 1972)}

This species (syn. T-2) appears to be confined to the arctic and subarctic zones of the Holarctic region. T. nativa is relatively common among bears, foxes, and dogs in this region and is reported from a wide variety of other mammals including wild boars, mustelids, felids, walrus, and seals (Rausch et al., 1956; Kjos-Hanssen, 1984; Roth, 1950; Madsen, 1961). However, in contrast to T. spiralis, T. nativa has very low infectivity for swine and rats (Dick, 1983; Murrell et al., 1986; Dame et al., 1987; Pozio et al., 1992b; Kapel et al., 1998). An outstanding distinguishing feature of this species is the high resistance of muscle larvae to freezing (Dick, 1983; Smith, 1983; Pozio et al., 1992b, 1994). Although this resistance is influenced by host species (Dick, 1983), the ability to withstand freezing presents a hazard to people who consume game such as bears. The distribution of Trichinella species and genotypes appears to be correlated with the environmental temperature (Shaikenov and Boev, 1983; Pozio et al., 1992b, 1994), and for T. nativa, the limiting southern isotherm is $-5^{\circ} \mathrm{C}$ in January (Pozio et al., 1996, 1998).

T. nativa can be uniquely characterized by two allozyme markers, ME and 6PGD which were found in at least 19 geographical isolates (La Rosa et al., 1992). T. nativa also can be identified by specifically binding the pT2.13 repetitive DNA probe generated by La Rosa et al. (1994) though some very weak hybridization was observed in Southern blots of one isolate each of T. britovi and T. nelsoni. T. nativa can be also identified by a characteristic, single 127 bp PCR fragment via multiplex PCR (Zarlenga et al., 1999) and by simultaneous restriction enzyme digestion of COX I amplified mtDNA using Mse I and Bsp 1286 which generates two restriction fragments of 13 and $57 \mathrm{bp}$ in length (Nagano et al., 1999). Wu et al. (1999) and Zarlenga et al. (1991) have used molecular techniques to generate other markers as well.

\subsection{T. britovi (Pozio et al., 1992)}

This species (syn. T-3), relatively common in sylvatic carnivores in Eurasia, has been recovered from a wide range of hosts, including carnivores (canids, felids) and bears and occasionally wild boars, horses, domestic pigs and man. Because its morphological and biological features are similar to that of $T$. spiralis, it is not surprising that it was only recently recognized as a separate species (Pozio et al., 1992a). It is distinct from T. spiralis in its low infectivity for rats, greater resistance to freezing, and moderate infectivity for swine, slow nurse cell development and low in vitro production of newborn larvae (Table 1). Although T. britovi may infect domestic pigs and horses (Kapel and Gamble, 2000; Pozio, 1998) and can serve as a source of infection to humans, its transmission is primarily among sylvatic hosts, probably due to its poor reproductive capacity in swine and synanthropic rodents (Table 1), thereby limiting transmission from wild animals to hosts associated with humans (Pozio, 1998).

T. britovi can be identified by a single unique allozyme ACP, and this was observed to be consistent in over 60 isolates of T. britovi examined by La Rosa et al. (1992). This same species specifically binds the pT3.4 repetitive DNA probe generated by La Rosa et al. (1994). Minor cross-hybridization with genotype Trichinella T-8 is partial foundation for the phylogenetic relationship between Trichinella T-8 and T. britovi (La Rosa and Pozio, 
2000). T. britovi can also be identified by two characteristic PCR fragments migrating at 127 and $253 \mathrm{bp}$ in multiplex PCR (Zarlenga et al., 1999). As with the DNA probe of La Rosa et al. (1994), multiplex PCR does not differentiate between T. britovi and Trichinella T-8. T. britovi can also be identified by a panel of five restriction fragments migrating at 22, 62, 64, 70 and 201 bp in length following Mse I digestion of COX I amplified mtDNA (Nagano et al., 1999). Mse I digestion, as with the DNA probe pT3.4 and multiplex PCR, cannot distinguish T. britovi from Trichinella T-8; however, this can be accomplished with an additional restriction enzyme digestion using Alu I which generates two restriction fragments 36 and $113 \mathrm{bp}$ in length (Nagano et al., 1999). Additional molecular markers have also been established by Wu et al. $(1998,1999)$ and Zarlenga et al. (1991).

\subsection{T. nelsoni (Britov and Boev, 1972), sensu stricto (Pozio et al., 1992a)}

This parasite (syn. T-7) occurs throughout equatorial Africa. Its host range includes primarily Hyaenidae and Felidae and occasionally Suidae and man. In most biological characteristics, this species is similar to T. spiralis, T. britovi and T. murrelli. However, it is distinguished biologically from $T$. spiralis in its low reproductive capacity in pigs and rats, low newborn larvae production in vitro and extended nurse cell development in mice (Table 1). Unlike T. britovi and T. nativa, T. nelsoni has very low resistance to freezing.

This species appears to be unusually tolerant to high temperatures (Table 1), perhaps a reflection of its adaptation to a warm climate (isotherm $30^{\circ} \mathrm{C}$ ). In distinction to all other species its muscle larvae may survive up to $60 \mathrm{~min}$ at $56^{\circ} \mathrm{C}$, while larvae of other species are killed within $10 \mathrm{~min}$ at this temperature (Boev and Sokolova, 1981). Because scavenging is a common means by which larvae in host muscle are passed to a new host, the ability of larvae to withstand high temperatures during host decomposition should be an adaptive advantage.

T. nelsoni can be identified by three unique allozymes ADA, GLDH, and TPI that were detected in two isolates of T. nelsoni (La Rosa et al., 1992). This species specifically binds the pT7.3 repetitive DNA probe generated by La Rosa and Pozio (2000). Alternatively, T. nelsoni can also be identified by two characteristic PCR fragments migrating at 155 and $404 \mathrm{bp}$ in multiplex PCR (Zarlenga et al., 1999) and by a PCR restriction fragment 223 bp in length following Mse I digestion of COX I amplified mtDNA (Nagano et al., 1999). Additional molecular markers have been generated by Wu et al. $(1998,1999)$ and Zarlenga et al. (1991).

\subsection{T. murrelli (Pozio and La Rosa, 2000)}

This species, recently described by Pozio and La Rosa (2000), was formerly identified as an infrasubspecific population, T-5, for North American isolates from wild animals (Pozio et al., 1992a). Sylvatic hosts include carnivores, and occasionally the parasite has been found in horses and people. Although this species is most similar to T. britovi, it is easily distinguished from other species by certain molecular features. As with all sylvatic species, T. murrelli has a very low reproductive capacity in pigs (much lower than T. britovi) and rats, low newborn larvae production in vitro, a very extended nurse cell development time and no resistance to freezing (Table 1). Cross breeding experiments demonstrated that this species is reproductively isolated from the other species (Pozio and La Rosa, 2000). This species is sympatric with a variant (T-6) of $T$. nativa. Its northern boundary is probably 
related to an isotherm of $-6^{\circ} \mathrm{C}$ in January, but its southern boundary (Mexico, Central and South America) is yet to be determined.

T. murrelli has yet to be characterized by any unique allozyme. At least 27 allozymes and 32 isolates have been tested and thus far the species can only be identified by several molecular characters (Pozio and La Rosa, 2000). Parasites of this species specifically bind the pUPB 3.7 repetitive DNA probe generated by Zarlenga et al. (1991). Further, T. murrelli genomic DNA generates two characteristic PCR fragments migrating at 127 and $316 \mathrm{bp}$ via multiplex PCR (Zarlenga et al., 1999) and three additional PCR restriction fragments 92, 126 and 201 bp by Mse I digestion of COX I amplified mtDNA (Nagano et al., 1999). Zarlenga et al. (1991) and Wu et al. $(1998,1999)$ have produced several other markers for differentiating T. murrelli.

\subsection{T. pseudospiralis (Garkavi, 1972)}

This species (syn. T-4) was the first non-encapsulating Trichinella discovered (Garkavi, 1972). T. pseudospiralis is notable not only for the lack of nurse cell generation in the host, but also for its ability to infect both birds (carnivorous or carrion-eating) and mammals (marsupials, rodents, carnivores, swine and occasionally, humans). In addition to these marked characteristics, T. pseudospiralis is also dissimilar to other species by a smaller length in larvae and adults (Table 1), moderate reproductive capacity in rats, and, with T. britovi, moderate reproductive capacity in pigs (Kapel and Gamble, 2000) and in wild boars (Kapel, 2000). In recent years, human outbreaks from swine have been reported (Jongwutiwes et al., 1998; Britov, 1997).

T. pseudospiralis can be identified by 12 unique allozymes ACP, ADA, ALAT, ALDO, GPD, LDH, EST, G6PD, GLDH, GOT, SOD and TPI of 27 examined; however, only two isolates of $T$. pseudospiralis were used to generate the allozyme profile (La Rosa et al., 1992). This species specifically binds the pTsp 5.32 repetitive DNA probe generated by Lindsay et al. (1995) and is further characterized by one or more bands migrating in the 300-360 bp range when used to analyze three isolates of T. pseudospiralis from Caucasus (Palearctic region), Tasmania (Australian region) and Alabama (Nearctic region) (Zarlenga et al., 1996, 1999). T. pseudospiralis can also be distinguished by the presence of a $419 \mathrm{bp}$ fragment in Mse I-digested, COX I-amplified mtDNA (Nagano et al., 1999). Several other PCR-derived techniques (Wu et al., 1997, 1999) and RFLP techniques (Zarlenga et al., 1991) are also available for identifying T. pseudospiralis.

\subsection{T. papuae (Pozio et al., 1999)}

This second non-encapsulating Trichinella species (syn. T-10) was recently described by Pozio et al. (1999) from a wild pig in Papua New Guinea. Experimentally, this species can infect laboratory mice, but unlike T. pseudospiralis it is not able to infect chickens. Another distinguishing feature is that the length of its muscle larvae is about $1 / 3$ greater than those of T. pseudospiralis. Crossbreeding experiments demonstrated that $T$. papuae cannot hybridize with other Trichinella species. Pozio et al. (1999) suggested that the non-encapsulating species represent a second evolutionary line and that the taxonomy of this group may need revision at the genus level. 
T. papuae has been analyzed only by the multiplex PCR test of Zarlenga et al. (1999). The recency of the discovery of this species has not yet permitted analysis by other methods to determine additional molecular markers. The PCR amplification of the ESV of an isolate of T. papuae using the primer set I produced a unique fragment of $240 \mathrm{bp}$ (Pozio et al., 1999).

\subsection{Genotypes of uncertain taxonomic status}

Trichinella T-6 has not yet been assigned a taxonomic position because of its biological and genetic similarity to T. nativa. As reported for T. nativa, larvae of Trichinella T-6 are highly resistant to freezing in muscles of carnivores (up to 34 months) (Worley et al., 1986). Isolates belonging to this genotype have been identified only in sylvatic hosts from Idaho, Montana, Ontario and Pennsylvania (Pozio, 2000) and have been found to interbreed (experimentally) with T. nativa (Pozio, unpublished data). As a result, identification of this genotype can be accomplished only by using a single unique allozyme, ACO (La Rosa et al., 1992), and PCR differentiation between T-6 and T. nativa is problematic (Appleyard et al., 1999). However, the multiplex PCR test of Zarlenga et al. (1999) generates two characteristic fragments that migrate at 127 and $210 \mathrm{bp}$ on agarose gels. The RAPD-derived PCR test of Nagano et al. (1999) does not produce the $57 \mathrm{bp}$ fragment characteristic of $T$. nativa that is generated following Mse I and Bsp 1286 I digestion. Additional molecular markers have also been established (Wu et al., 1999; Zarlenga et al., 1991).

Trichinella T-8 consists of only three isolates from sylvatic carnivores of South Africa and Namibia. This genotype is capable of interbreeding with $T$. britovi under laboratory conditions (La Rosa and Pozio, 2000). No unique allozyme distinguishes this genotype (La Rosa et al., 1992); however, Trichinella T-8 can be distinguished by specifically binding the pT8.3 repetitive DNA probe generated by La Rosa and Pozio (2000) and can also be characterized by PCR restriction fragments migrating at 66, 149 and 204 bp following Alu I restriction enzyme digestion of PCR-amplified COX I mtDNA (Nagano et al., 1999). Wu et al. (1999) have produced other molecular markers to distinguish this genotype.

Trichinella T-9 is related to T. britovi and interbreeding has been observed under laboratory conditions (Pozio, unpublished data). Two isolates from sylvatic carnivores of Japan (Nagano et al., 1999), and previously identified as T. britovi (Pozio et al., 1996) constitute this genotype. This genotype can be identified by two Ssp I restriction fragments, 650 and $1500 \mathrm{bp}$ in length, originating from the gene encoding the $43 \mathrm{kDa} \mathrm{ES}$ antigen digested with (Wu et al., 1999) and two fragments, 92 and 327 bp in length, following Mse I digestion of PCR amplified COX I mtDNA (Nagano et al., 1999).

An interesting isolate of Trichinella from Crocodylus niloticus has been reported from farmed crocodiles in Zimbabwe (Mukaratirwa and Foggin, 1999). Because this isolate has yet to be identified to species, its systematic status is uncertain, but recent studies have found it to be highly infective for rats and pigs (Mukaratirwa and Foggin, 1999). Rarely, small intracellular nematodes other than Trichinella larvae may be found in the muscles of vertebrates including man (Andrews et al., 1997). An interesting example in man was described recently in Australia that apparently involved a dual infection with Trichinella (Andrews et al., 1997) and a new nematode (Haycocknema perplexum) of the family Robertdollfusidae (Spratt et al., 1999). Because nematodes other than these, such as Ancylostoma and Dracunculus, may rarely be found in myofibers, the morphological 
features and/or molecular identification of such larvae must be carefully determined (Spratt et al., 1999). It should also be recognized that, under certain conditions, some reptiles can be rendered susceptible to Trichinella. Cristen and Perian (1999) reported that vipers, held at $37-39^{\circ} \mathrm{C}$, could be experimentally infected with an unidentified species of Trichinella; interestingly, the larvae at 30 days post-infection were unencapulsated in the muscle.

\section{Discussion}

Reservations about the species level systematics (Dick, 1983; Bessonov, 1998) of the genus Trichinella have been related to concerns about the possibility of gene flow among the "species" (Pozio et al., 1995, 1997). While there is no single definition of what constitutes a species, from both a philosophical and practical viewpoint, it is desirable to be able to distinguish between populations that are unique with little or no gene flow between them and populations where sufficient gene flow exists so that shared characteristics can be expected. In addition to the evidence provided by the controversial, but frequently used experimental mating tests for reproductive isolation among species of Trichinella, arguments have been made that populations that maintain, in sympatry, the degree of differences described among species of this genus, must be considered to be species by definition (Mayr, 1969; Pozio et al., 1992a). However, doubt has existed about whether the species were in true sympatry because of limited possibilities for mating in nature between two populations due to a short adult intestinal phase and strong immunity to reinfection (Pozio et al., 1992a). Recently, however, several examples of naturally-occurring multiple species infections have been discovered (Pozio et al., 1995, 1997; Pozio, 2000). These observations that more than one species of muscle larvae are occasionally found in a single host provide strong evidence for sympatry for a number of these species.

Because of this, we have considered whether a population of muscle larvae might be similar to a clone of protozoan organisms. However, nematodes of this genus reproduce sexually and have hologonic reproductive organs in both males and females. Hologonic gonads have a germination zone for gametes that runs the entire length of the organ, in contrast to all of the gametes originating from a single cell (telogonic gonads) as in most nematodes (Chitwood and Chitwood, 1950). Individual nematodes with hologonic gonads have been shown to be capable of producing significantly different sized eggs, suggestive of a higher level of genetic variability among gametes from hologonic gonads than from telogonic gonads. The hologonic gonad may be hypothesized to be an adaptation to increase genetic variability in nematodes with adult populations that are small in numbers or in reproductive life span. Because of this unusual reproductive feature, Trichinella larvae in a single host may be more genetically variable than one might expect if telogonic gonads were involved. This is an area that needs further investigation.

A second area needing substantially more study is the application of biochemical and molecular characters to phylogenetic studies on the genus Trichinella. In 1992, La Rosa et al. (1992) were the first to generate a dendrogram based upon unweighted pair group method of analysis (UPGMA) of isoenzyme data from a large investigation involving over 152 isolates and 27 enzyme systems. These data were combined with other biological and biochemical data in the construction of a new taxonomic structure for this parasite 
group (Pozio et al., 1992a,b). Two years later, several groups (Bandi et al., 1995; Arribas et al., 1994; Dupouy-Camet et al., 1994) attempted to use random amplified polymorphic DNA (RAPD) to generate datasets for UPGMA comparisons. Comparison of the results from these studies suggested that the conditions for RAPD-PCR and choice of primers could drastically affect data acquisition and complicate assessment of similarities among genotypes. It was not until 1998 that Zarlenga (1998) constructed a dendrogram based upon distance algorithms and DNA sequence alignment data from Trichinella mitochondrial, large subunit, ribosomal DNA, that was substantially congruent with the conclusions drawn from the isoenzyme data. Unfortunately, UPGMA does not address data in a manner that assesses evolutionary relationships among parasites within the genus, but looks only at the similarities and/or differences to group the organisms. Given the uniqueness of this genus, namely, that all genotypes are readily available for analysis and that multiple isolates of each genotype can be easily propagated under laboratory conditions, it is clear that a unique opportunity exists to perform an in-depth study of both interspecific as well as intraspecific variation within the genus Trichinella. Such a study will not only require the generation of new datasets from other gene systems, but a re-evaluation of existing data, as well. Such a compilation of information will eventually permit us to construct a phylogenetic tree based upon more accepted practices for assimilating genotypic interrelationships, i.e. parsimony or maximum likelihood analyses.

\section{References}

Andrews, J.R.H., Ainsworth, R., Pozio, E., 1997. Nematodes in human muscle. Parasitol. Today 13, 488-489.

Appleyard, G.D., Conboy, G., Gajadhar, A.A., 1996. Trichinella spiralis in sylvatic hosts from Prince Edward Island. J. Wildl. Dis. 34, 158-160.

Appleyard, G.D., Zarlenga, D., Pozio, E., Gajadhar, A.A., 1999. Differentiation of Trichinella genotypes by polymerase chain reaction using sequence specific primers. J. Parasitol. 831, 556-559.

Arakawa, A., Todd, A.C., 1971. Comparative development of temperate zone and arctic isolates of Trichinella spiralis in the white mouse. J. Parasitol. 57, 526-530.

Arribas, B., Siles, M., Bolás, F., Martínez-Fernández, A.R., 1994. Random amplified DNA polymorphism within Trichinella species and isolates. In: Campbell, W.C., Pozio, E., Bruschi, F. (Eds.), Trichinellosis. Istituto Superiore di Sanitá Press, Rome, pp. 55-60.

Bandi, C., La Rosa, G., Bardin, M.G., Damiani, G., Comincini, S., Tasciotti, L., Pozio, E., 1995. Random amplified polymorphic DNA fingerprints of the eight taxa of Trichinella and their comparison with allozyme analysis. Parasitology 110, 401-407.

Bessonov, A.S., 1998. Taxonomic position of nematodes from the genus Trichinella Railliet, 1895. Meditsinskaya Parazit. Parazitar. Bolezni. 1, 3-6 (in Russian).

Boev, S.N., Sokolova, L.A., 1981. Primary diagnostics of sibling-species of Trichinella. Wiad. Parazytol. 27, 483-487.

Boyd, D., de Vos, T., Klassen, G., Dick, T.A., 1989. Characterization of the ribosomal DNA from Trichinella spiralis. Mol. Biochem. Parasitol. 35, 67-72.

Britov, V.A., 1974. The importance of differentiating Trichinella spiralis for the prophylaxis of trichinellosis. In: Kim, C.W. (Ed.), Trichinellosis. Text Educational Publications, New York, pp. 567-570.

Britov, V.A., 1997. Trichinellosis in Kamchatka. Wiad. Parazytol. 43, 287-288.

Britov, V.A., Boev, S.N., 1972. Taxonomic rank of various strains of Trichinella and their circulation in nature. Vestin. Akad. Nauk. SSSR 28, 27-32 (in Russian).

Chadee, K.C., Dick, T.A., 1982. Biological characteristics and host influence on a geographical isolate of Trichinella (Woolverine: $55^{\circ} 00^{\prime} \mathrm{N}, 100^{\circ} 00^{\prime} \mathrm{W}, 1979$ ). J. Parasitol. 68, 451-456. 
Chambers, A.E., Almond, N.M., Knight, M., Simpson, A.J., Parkhouse, R.M., 1986. Repetitive DNA as a tool for the identification and comparison of nematode variants: application to Trichinella isolates. Mol. Biochem. Parasitol. 21, 113-120.

Chitwood, M.D., Chitwood, B.G., 1950. Introduction to Nematology. University Park Press, Baltimore.

Cristen, G., Perian, A., 1999. Experimental infestation with Trichinella larvae in vipers. Revista Romana de Parasitologies 9, 45.

Dame, J.B., Murrell, K.D., Worley, D.E., Schad, G.A., 1987. Trichinella spiralis: genetic evidence for synanthropic subspecies in sylvatic hosts. Exp. Parasitol. 64, 195-203.

Dick, T.A., 1983. Species and intraspecific variation. In: Campbell, W.C. (Ed.), Trichinella and Trichinosis. Plenum Press, New York, pp. 31-73.

Dupouy-Camet, J., Robert, F., Guillou, J.P., Vallet, C., Perret, C., Soulé, C., 1994. Genetic analysis of Trichinella isolates with random amplified polymorphic DNA markers. In: Campbell, W.C., Pozio, E., Bruschi, F. (Eds.), Trichinellosis. Istituto Superiore di Sanitá Press, Rome, pp. 83-88.

Garkavi, B.G., 1972. Species of Trichinella isolated from wild animals. Veterianariya 10, 90-91.

Gould, S.E., 1970. History. In: Gould, S.E. (Ed.), Trichinellosis in Man and Animals. Charles C. Thomas, Springfield, IL, pp. 3-46.

Gretillat, S., Vassiliades, G., 1968. Receptives comparees du chat et du pore domestiques a la souche ouest-africaine de Trichinella spiralis (Owen, 1835). C.R. Acad. Sci. 266, 1139-1141.

Hulinska, D., Shaikenov, B., 1983. A comparative study on the development and the structure of sperms of Trichinella nativa, T. pseudospiralis and T. spiralis. Folia Parasitol. 30, 31-36.

Jongwutiwes, S., Chantachum, N., Kraivichian, P., Siriyasatien, P., Putaporntip, C., Tamburrini, A., La Rosa, G., Sreesunpasirikul, C., Yingyourd, P., Pozio, E., 1998. First outbreak of human trichinellosis caused by Trichinella pseudospiralis. Clin. Inf. Dis. 26, 111-115.

Kapel, C.M.O., 2000. Experimental infections with sylvatic and domestic Trichinella spp. in wild boars infectivity, muscle larvae distribution, and antibody response. J. Parasitol. 93, 263-278.

Kapel, C.M.O., Gamble, H.R., 2000. persistence and antibody response to domestic and sylvatic Trichinella spp. in experimentally infected pigs. Int. J. Parasitol. 30, 215-221.

Kapel, C.M.O., Webster, P., Lind, P., Pozio, E., Henriksen, S.-A., Murrell, K.D., Nansen, P., 1998. Trichinella spiralis, T. britovi, and T. nativa: infectivity larval distribution in muscle and antibody response after experimental infections of pigs. Parasitol. Res. 84, 264-271.

Kjos-Hanssen, B., 1984. Trichinella isolates from polar bears in Svalbard. Freeze resistance and infectivity in rats and swine. Nord. Vet. Med. 36, 57-61.

Klassen, G.R., Thiessen, J.P., Dick, T.A., 1986. Strain-specific 1.7 kilobase-repetitive deoxyribonucleic acid sequence family in Trichinella spiralis. Mol. Biochem. Parasitol. 21, 227-233.

Kozar, Z., Kozar, M., 1965. A comparison of the infectivity and pathogenicity of Trichinella spiralis strains from Poland and Kenya. J. Helminthol. 39, 19-34.

Kruger, S.P., Collins, M.H., van Niekerk, J.W., McCully, R.M., Basson, P.A., 1969. Experimental observations on the South African strain of T. spiralis. Wiad. Parazytol. 15, 546-554.

La Rosa, G., Pozio, E., 2000. Molecular investigation of African isolates of Trichinella reveals genetic polymorphism in Trichinella nelsoni. Int. J. Parasitol. 30, 663-667.

La Rosa, G., Pozio, E., Rossi, P., Murrell, K.D., 1992. Allozyme analysis of Trichinella isolates from various host species and geographic regions. J. Parasitol. 78, 641-646.

La Rosa, G., Tasciotti, L., Pozio, E., 1994. DNA repetitive probes for the characterization and identification of Trichinella parasites. In: Campbell, C.W., Pozio, E., Bruschi, F. (Eds.), Trichinellosis. Istituto Superiore di Sanitá Press, Rome, Italy, pp. 89-94.

Lichtenfels, J.R., Murrell, K.D., Pilitt, P.A., 1983. Comparison of three subspecies of Trichinella spiralis by scanning electron microscopy. J. Parasitol. 69, 1131-1140.

Lindsay, D.S., Zarlenga, D.S., Gamble, H.R., Al-Yaman, F., Smith, P.C., Blagburn, B.L., 1995. Isolation and characterization of Trichinella pseudospiralis (Garkavi, 1972) from a black vulture (Coragyps atratus). J. Parasitol. 81, 920-923.

Madsen, H., 1961. The distribution of Trichinella sprialis in sledge dogs and wild mammals in Greenland. Medd. Groenl. 159, 1-124.

Martinez-Fernandez, A.R., Arribas, B., Bolas, F., 1998. Freezing resistance of Spanish Trichinella isolates (T. sprialis and T. britovi). In: Ortega-Pierres, G., Gamble, R., van Knapen, F., Wakelin, D. (Eds.), Trichinellosis. Centro de Investigacion y de Estudios Avanzados del IPN, Mexico, D.F. Mexico, pp. 99-105. 
Mayr, E., 1969. Principles of Systematic Zoology. McGraw-Hill, New York, 427 pp.

Minchella, D.J., Branstetter, B.A., Kazacos, K.R., 1989. Molecular characterization of sylvatic isolates of Trichinella spiralis. J. Parasitol. 75, 388-392.

Mukaratirwa, S., Foggin, C.M., 1999. Infectivity of Trichinella sp. isolated from Crocodylus niloticus to the indigenous Zimbabwean pig (Mukota). Int. J. Parasitol. 29, 1129-1131.

Murrell, K.D., Leiby, D.A., Duffy, C., Schad, G.A., 1985. Susceptibility of domestic swine to wild animal isolates of Trichinella spiralis. In: Kim, C.W. (Ed.), Trichinellosis. State University of New York Press, Albany, pp. 301-305.

Murrell, K.D., Leiby, D.A., Duffy, C.H., Schad, G.A., 1986. Comparative infectivity of Trichinella spiralis spiralis (domestic swine) and T. spiralis nativa (polar bear) for arctic foxes. Proc. Helminthol. Soc. Wash. 53, 286-288.

Murrell, K.D., Stringfellow, F., Dame, J.B., Leiba, D.A., Schad, G.A., 1987. Trichinella spiralis in an agricultural ecosystem. II. Evidence for natural transmission of T. spiralis from domestic swine to wildlife. J. Parasitol. 73, 103-109.

Mydynski, L.J., Dick, T.A., 1985. The use of enzyme polymorphisms to identify genetic differences in the genus Trichinella. J. Parasitol. 71, 671-677.

Nagano, I., Wu, Z., Matsuo, A., Pozio, E., Takahashi, Y., 1999. Identification of Trichinella isolates by polymerase chain reaction-restriction fragment length polymorphism of the mitochondrial cytochrome c oxidase subunit I gene. Int. J. Parasitol. 29, 1113-1120.

Nelson, G.S., Mukundi, J., 1963. A strain of Trichinella spiralis from Kenya of low infectivity to rats and domestic pigs. J. Helminthol. 37, 329-338.

Nelson, G.S., Blackie, E.J., Mukundi, J., 1966. Comparative studies on geographical strains of Trichinella spiralis. Trans. R. Soc. Trop. Med. Hyg. 60, 471-480.

Owen, R., 1835. Description of a microscopic entozoon infesting the muscles of the human body. Trans. Zool. Soc. London 1, 315-324.

Pozio, E., 1998. Trichinellosis in the European Union: Epidemiology, ecology and economic impact. Parasitol. Today 14, 35-38.

Pozio, E., 2000. The domestic, synanthropic and sylvatic cycles of Trichinella and the flow among them. Vet. Parasitol. 93, 241-262.

Pozio, E., La Rosa, G., 2000. Trichinella murrelli sp.: etiological agent of sylvatic trichinellosis in temperate areas of North America. J. Parasitol. 86, 134-139.

Pozio, E., La Rosa, G., Rossi, P., 1989. Trichinella Reference Centre. Parasitol. Today 5, 169-170.

Pozio, E., La Rosa, G., Murrell, K.D., Lichtenfels, J.R., 1992a. Taxonomic revision of the genus Trichinella. J. Parasitol. 78, 654-659.

Pozio, E., La Rosa, G., Rossi, P., Murrell, K.D., 1992b. Biological characterization of Trichinella isolates from various host species and geographical regions. J. Parasitol. 78, 647-653.

Pozio, E., La Rosa, G., Amati, M., 1994. Factors influencing the resistance of Trichinella muscle larvae to freezing. In: Campbell, W.C., Pozio, E., Bruschi, F. (Eds.), Trichinellosis. Istituto Superiore di Sanitá Press, Rome, pp. 173-178.

Pozio, E., Bandi, C., La Rosa, G., Jarvis, T., Miller, I., Kapel, C.M., 1995. Concurrent infection with sibling Trichinella species in a natural host. Int. J. Parasitol. 25, 1247-1250.

Pozio, E., La Rosa, G., Yamaguchi, T., Saito, S., 1996. Trichinella britovi from Japan. J. Parasitol. 82, 847-849.

Pozio, E., Serrano, F.J., La Rosa, G., Reina, D., Perez-martin, E., Navarrete, I., 1997. Evidence of potential gene flow in Trichinella spiralis and in Trichinella britovi in nature. J. Parasitol. 83, 163-166.

Pozio, E., Miller, I., Jarvis, T., Kapel, C.M.O., La Rosa, G., 1998. Distribution of sylvatic species of Trichinella in Estonia according to climate zones. J. Parasitol. 84, 193-195.

Pozio, E., Owen, I.L., La Rosa, G., Sacchi, L., Rossi, P., Corona, S., 1999. Trichinella papuae n. sp. (Nematoda), a new non-encapsulated species from domestic and sylvatic swine of Papua New Guinea. J. Parasitol. 29, $1825-1839$

Rausch, R.L., Babero, B.B., Rausch, R.V., Schiller, E.L., 1956. Studies on the helminth fauna of Alaska. XXVII. The occurrence of larvae of Trichinella spiralis in Alaskan mammals. J. Parasitol. 42, 259-271.

Roth, H., 1950. Nouvelles experiences sur la trichinose awe considerations speciaoles sur son existence dans les regions arctiques. Bull. O.I.E. 34, 197-220.

Shaikenov, B., Boev, S.N., 1983. Distribution of Trichinella species in the Old World. Wiad. Parazytol. 29, 595608 . 
Smith, H.J., 1983. Differentiation of Trichinella spiralis spiralis and Trichinella spiralis nativa based on resistance to low temperature refrigeration. Can. J. Comp. Med. 47, 501-502.

Snyder, D.E., Zarlenga, D.S., La Rosa, G., Pozio, E., 1993. Biochemical, biological and genetic characterization of a sylvatic isolate of Trichinella. J. Parasitol. 79, 347-352.

Spratt, D.M., Beveridge, I., Andrews, J.R., Dennett, X., 1999. Haycocknema perplexum n.g., n. sp. (Nematoda: Robertdollfusidae): an intramyofibre parasite in man. Syst. Parasitol. 43, 123-131.

Webster, P., Kapel, C.M.O., Bjorn, H., 1999. Reproductivity of nine Trichinella isolates in guinea pigs and mice. Acta Vet. Scand. 40, 93-95.

Worley, D.E., Seesee, F.M., Espinosa, R.H., Sterner, M.C., 1986. Survival of sylvatic Trichinella spiralis isolates in frozen tissue and processed meat products. J. Am. Vet. Assoc. 189, 1047-1049.

Wu, Z., Nagano, I., Fukumoto, S., Saito, S., Yamaguchi, T., Pozio, E., Takahashi, Y., 1997. Polymerase chain reaction primers to identify Trichinella spiralis or T. pseudospiralis. Parasitol. Int. 46, 149-154.

Wu, Z., Nagano, I., Takahashi, Y., 1998. The detection of Trichinella with polymerase chain reaction (PCR) primers constructed using sequences of random amplified polymorphic DNA (RAPD) or sequences of complementary DNA encoding excretory-secretory (E-S) glycoproteins. Parasitology 117, 173-183.

Wu, Z., Nagano, I., Pozio, E., Takahashi, Y., 1999. Polymerase chain reaction-restriction fragment length polymorphism (PCR-RFLP) for the identification of Trichinella isolates. Parasitology 118, 211-218.

Zarlenga, D.S., 1998. Molecular aspects of speciation in the genus Trichinella. In: Ortega-Pierres, G., Gamble, R., van Knapen, F., Wakelin, D. (Eds.), Trichinellosis. Centro de Investigación y de Estudios Avanzados del IPN, D.F. Mexico, pp. 43-46.

Zarlenga, D.S., Barta, J.R., 1990. DNA analysis in the diagnosis of infection and in the speciation of nematode parasites. Rev. Sci. Tech. Off. Int. Epiz. 9, 533-554.

Zarlenga, D.S., Murrell, K.D., 1989. Molecular cloning of Trichinella spiralis ribosomal RNA genes: application as genetic markers for isolate classification. In: Tanner, C.E. (Ed.), Trichinellosis. CSIC Press, Madrid, pp. 35-40.

Zarlenga, D.S., Al-Yaman, F., Minchella, D., La Rosa, G., 1991. A repetitive DNA probe specific for a North American sylvatic genotype of Trichinella. Mol. Biochem. Parasitol. 48, 131-138.

Zarlenga, D.S., Aschenbrenner, R.A., Lichtenfels, J.R., 1996. Variations in microsatellite sequences provide evidence for population differences and multiple ribosomal gene repeats within Trichinella pseudospiralis. J. Parasitol. 82, 534-538.

Zarlenga, D.S., Chute, M.B., Martin, A., Kapel, C.M.O., 1999. A multiplex PCR for unequivocal differentiation of six encapsulated and three non-encapsulated genotypes of Trichinella. Int. J. Parasitol. 29, 141-149.

Zimoroi, I., 1963. Natural foci of trichinellosis and foci associated with man in the Kursk region. Med. Parazit. Bolenzi, Moskva 32, 177-180. 